\section{$\underset{\substack{\text { hommes } \\ \text { \& migrations }}}{ }$}

\section{Hommes \& migrations}

Revue française de référence sur les dynamiques

migratoires

$1314 \mid 2016$

Migrations chinoises et générations

\title{
Gaspard Koenig, Kidnapping
}

Paris, Grasset, 2015, 365 p., $19 €$

\section{Mustapha Harzoune}

\section{(2) OpenEdition}

\section{Journals}

\section{Édition électronique}

URL : http://journals.openedition.org/hommesmigrations/3683

DOI : 10.4000/hommesmigrations.3683

ISSN : 2262-3353

\section{Éditeur}

Musée national de l'histoire de l'immigration

\section{Édition imprimée}

Date de publication : 1 avril 2016

Pagination : 180-181

ISBN : 978-2-919040-35-3

ISSN : $1142-852 X$

\section{Référence électronique}

Mustapha Harzoune, " Gaspard Koenig, Kidnapping », Hommes \& migrations [En ligne], 1314 | 2016, mis en ligne le 19 septembre 2016, consulté le 24 septembre 2020. URL : http://journals.openedition.org/ hommesmigrations/3683; DOI : https://doi.org/10.4000/hommesmigrations.3683 


\section{Gaspard Koenig}

Kidnapping

Paris, Grasset, 2015,

365 pages, $19 €$

Dans Kidnapping tout s'emboite, coule, parfaitement huilé. On passe du Londres de la finance à un monastère roumain des Carpates. On patauge dans les mœurs européennes, celles des tractations entre institutions et gouvernements et, dans le même mouvement, on plonge dans l'intime de l'exil roumain à Londres.

Roxy, nounou roumaine, est employée par David et Ivana, son épouse croate, pour veiller Georges, leur rejeton. Elle est payée au lance-pierres mais au moins les corvées de chiottes et de tambouille lui sont épargnées. Roxy économise pour ouvrir une pharmacie au pays mais son "statut d'esclave domestique" lui fait honte quand son fiancé vient la visiter. Et quand s'éloignent les perspectives du retour, "sa révolte contre les bourgeois londoniens" devient "une envie d'abord honteuse, puis de plus en plus assumée, de gagner sa place à leurs côtés". Roxy ne fréquente pas les "habitants de cette ville inconnue". Les Roumains préfèrent se retrouver entre eux. Comme à la gare routière de Victoria, où les cars embarquent pour la Roumanie, débarquent les nouveaux immigrés et livrent les colis expédiés "du bled".

Dans un de ces goûters chics pour enfants de la bonne société, elle sauve Georges d'un étouffement certain. Par cette salvatrice intervention, Ivana comprend que Roxy n'est pas "une sousmerde" analphabète, que dans son pays elle était infirmière. Jusque-là, seule Rose, la mère de David, lui témoignait de l'humanité, l'appelant par son prénom, Ruxandra. II faut dire que la mamie tranche : elle n'aime pas ce que son fils est devenu - un banquier ! L'incarnation d'un système qu'elle exècre. Elle préférerait le voir jouer Shakespeare sur les planches et continue à le morigéner: "Le jour où l'on cesse d'aider les autres, c'est le jour où l'on commence à vieillir."Tiens! Tiens!

David travaille à la Banque européenne. Ses velléités de notabilité patinent. Jusqu'à ce qu'il obtienne de piloter le tronçon Bucarest-Suceava d'une autoroute qui doit relier la Grèce et la Finlande. Arrive alors le tableau des lobbies, de la corruption, des détournements de fonds, des petits arrangements et des combines du genre: "L'autoroute passe chez vous mais, en échange, 'vous gardez vos Gitans"' ! Pour faire avaler la pilule aux protestataires, David transforme le projet "en produit culturel". L'autoroute devient la route des monastères. On modernise en valorisant l'héritage ! Et de gazouiller la petite musique d'une Europe chrétienne, éternelle et résistante versus l'islamisation rampante. Ce qui se joue aussi est l'opposition (un brin binaire) de deux mondes, celui d'une Europe soumise au credo néolibéral et à une modernisation faisandée par la finance versus celui, paisible, des nonnes du monastère de Varatec hostiles au projet. Varatec ! La région d'origine de Roxy ! C'est là où le destin du banquier et celui de la nounou 
immigrée vont se croiser. Lorsque Roxy se sentira flouée par ses employeurs, sa culpabilité se transformera en rage. Alors, dans une scène qui rappelle le personnage de Nino Garofalo dans
Pain et chocolat (1974), "elle raccrochait son costume d'immigrée méritante et redevenait elle-même". Car il faut bien que les masques tombent.

M. H.

\section{Paola Pigani}

Venus d'ailleurs

Paris, Liana Levi, 2015, 171 pages, $17 €$

1999, Mirke et Simona, te frère et la seeur, débarquent ì Lyon, en demandeurs d'asite attirés par la lumière du triptyque répu blieain. Is ont fuit la guerre et les persécutions en Albanie. Eomme tous les exilés, its portent le poids des abandons et de la culpabilité. Partir c'est aussi "trahir les siens". Très vite, ils se débrouillent. S'activent. Cha eun avec ses fantêmes. Airke travaille sur un chantier, Babeldel'humanitéen bleu de travail. Simona est employée dans un magasin discount. Sila seur seprojette avec frénésie dans l'avenir,te frère reste hanté par le souvenir de son neveu, et parson frère qui a rejoint les rangs de l'UCK." $M$ HOi,je me regarde dans te miroir de la France et je me trouve jolie" dit Simona, quand Mirko-s'aven ture dans les "zones" tristes et reculées de la ville. II bombe sa solitude ì coup de graffs, "comme des sris qui tiennent [sur]les mursécaillés". La frichedes graf feurs et muralistes, usines désaffectées et murs à l'abandon, éest la galerie à eielouvert où se figent des mondes dis parus, défaits, celui de l'exilé, celuides ouvriers. Simona avance; et vite. Cache ses souvenirs, dissimule sa tristesse dans une langue qu'elle seute com prend. Mirko, lui, disloqué, traine. Pour tant, magie de l'art, de la littérature et de l'amour, it reste sensible au monde quil'entoure. Chez Pierre, it rêve devant un atlas. Le libraire lui offre un Pré vert, un-Cendrars, lui parle de René Ley naud. La poésie comme ouverture ì soi et aux autres. II rencontre Agathe qui, dans une formule shakespearienne, se veut rassurante: "Sije te mords, tu as mal, tu cries. C'est la preuve que tues vivat. LA RREUVE." Quand pour Airke, eette preuve est dans cet amour qui, "le temps d'une étreinte fait oublier l'hi ver, les étrangers, la France, I'Albanie, le Kosovo..." Venus d'ailleurs n'assène pas de réponses bien ficelées aux ques tions du moment, mais offre beauté et hauteur de la littérature-de-sai sir la part humaine, l'imprévu, de réin venter et pourquoi pas de transfigu rer le réel. Cette littérature ne-cherche pas ì changer le monde. Juste ì enri thir les perceptions, élargir les regards, faconter les interstices du monde et sa part rêvée. Elle lave les bouches et tes âmes de ce goût de cendres laissé par les mots des phraseurs télévisuels adeptes du chiffre roi, des bréviaires et des vade mecum. Paola Pigani raconte 